\title{
Scoring the HIVIAIDS Awareness Campaign Goal: Evidence from a Historically Disadvantaged Higher Education Institution in South Africa
}

Costa Hofisi

\author{
North West University, Department of Public Administration
}

\author{
Shamiso Kachidza
}

University of Fort Hare

\author{
Doi:10.5901/mjss.2013.v4n6p295
}

\begin{abstract}
The purpose of the study was to assess the impact of HIVIAIDS awareness campaigns on the sexual behaviour of students at the University of Fort Hare, Alice campus. The research was specifically aimed at establishing whether HIVIAIDS awareness campaigns are exerting any significant changes on the sexual behaviour of students at the University of Fort Hare. The research was informed by the health belief model and its variables namely, perceived threats, perceived barriers and self efficacy. A combination of qualitative and quantitative research methodologies was employed and semi-structured questionnaires were used to collect data. High perceived threats observed among the students helped in reaching at the conclusion that HIVIAIDS awareness campaigns at the University of Fort Hare are positively impacting on the sexual behaviour of students basing results on the sample of respondents used in the study. However the research showed high perceived barriers when it comes to voluntary counselling and testing. Respondents also showed that they were afraid of stigmatisation if they go for VCT and found out that they were HIV positive. Since the health belief model states that high perceived barriers will lead people to avoid health risking behaviour and readily indulge in risky sexual behaviour, we argue that HIVIAIDS awareness campaigns have failed to a certain extend in terms of promoting safe sexual. It is against this background that we argue that due to HIVIAIDS misconceptions and other HIVIAIDS myths discovered there is need for a paradigm shift in awareness campaigns for them to be multidimensional. The article also recommends that to improve the effectiveness of HIVIAIDS awareness campaigns in reducing barriers related to VCT, there is need to constantly send awareness messages to students wherever and whenever necessary and not just during the campaigns.
\end{abstract}

Key words: HIVIAIDS, awareness campaigns, perceived threats, perceived barriers and self efficacy.

\section{Introduction}

HIVIAIDS has become the main cause of death in sub-Saharan Africa. The UNAIDS (2004) pointed out that in a belt of countries across Southern Africa, HIVIAIDS prevalence is maintaining alarmingly high levels in the general population. It has been noted that seven out ten newly infected people are in Africa and $85 \%$ of those who have died of AIDS and 95 $\%$ of HIVIAIDS orphans are also in Africa (UNAIDS, 2004). In South Africa alone, the rate of HIVIAIDS has been rising at an alarming rate.

The head of the Medical Research Council (MRC) in South Africa has stated that HIVIAIDS accounted for 336000 deaths between mid 2005 and mid 2006.This is an shocking figure and clearly shows how the deadly HIVIAIDS pandemic is claiming a lot of lives. The reasons why the epidemic has spread so rapidly in South Africa are many and complex. These include high levels of untreated STIs;the growing commercial sex industry;high levels of poverty and income inequality; malnutrition; unemployment; poor education; gender inequality; the entrenched system of migrant labour; a low level of condom usage and social norms that accept or encourage high numbers of sexual partners (Parry \& Abdool-Karim, 1999).

It has been noted that HIVIAIDS is claiming the economically active population. What is worrying is that universities carry a significant number of the economically active who are prone to HIVIAIDS infection. According to Chetty (2000), the challenge of HIVIAIDS looms larger in African tertiary institutions and is more deeply rooted than on other continents. The researchers felt prompted to study the impact of HIVIAIDS awareness campaigns on the sexual behaviour of students because universities bring together a large number of young adults at the peak years of sexual activity and 
experimentation. It has been noted that HIVIAIDS infections mostly occur through sexual intercourse with infected partners. Easy access to alcohol, peer pressure and freedom from parents at universities also create a very high risk environment from an HIVIAIDS perspective.

The absence of biomedical remedies for HIVIAIDS makes awareness campaigns targeting behavioural change to be the remedy that is left to society against the deadly HIVIAIDS pandemic. Awareness campaigns are important because they make HIVIAIDS issues visible and they prompt people to change their attitudes concerning HIVIAIDS. If awareness campaigns are effective, they act as eye openers to students at the University of Fort Hare and hopefully students will in turn influence their communities.

\section{Conceptual Issues}

\subsection{HIVIAIDS}

The Acquired Immune Deficiency Syndrome (AIDS) is caused by a Human Immunodeficiency Virus and is arguably the most serious infectious disease epidemic of modern times. HIVIAIDS not only spread rapidly but extensively since its emergency in 1981(Makalima, 2003). The Human Immunodeficiency Virus on the other hand is a member of a family of viruses known as retroviruses and are characterised by the insidious onset of the disease they cause and the retrovirus attacks white blood cells also known as T-Cells in the body (Cox, 1996).

According to Van Dyk (2001) the term acquired is used to explain the effect of HIV in the human body because it is a disease that is not inherited. Immunity refers to the body's natural inherent ability to fight against infection and disease (Van Dyk, 2001). Deficiency refers to the immune system of the body that has been damagedsuch that it cannotfight against infections. A syndrome refers to a collection or set of specific signs and symptoms occurring together characteristic of a pathological condition (Van Dyk, 2001). The effects of HIV on the body result in a severely reduced immune system,leaving the body susceptible to various forms of infection and diseases (Cox,1996).

\subsection{HIV/AIDS awareness}

According to Makalima (2003) HIVIAIDS awareness refers to the extensive knowledge of HIVIAIDS, including causes, effects and ways to combat the spread of this pandemic. Most campaigns on HIVIAIDS focus primarily on messages of consistent and correct condom use for the prevention of the transmission of the virus (Makalima, 2003). Although many young people are aware and know that condoms are the only contraceptive method that protects against STI and HIV infection, many of them still do not use condoms. According to Makiwane and Mokomane (2010) resistance to safe sex goes beyond demonstration and conception of the facts into the depths of people's social exchanges, their experiences of the sexuality and actual power. According to Gray et al (2008) the awareness initiative, Soul City, reported a high awareness level of AIDS and HIV transmission, even in rural areas. Despite the high level of awareness, an aura of mystery and confusion means of transmission and the severity of the epidemic still exist in South Africa.

\subsection{HIVIAIDS prevalence in South Africa}

In South Africa, the epidemic was first identified in 1982, when two homosexual men were reported to have died of AIDS related illness (Togni, 1997). Since then, the epidemic has been growing fast with an estimated 1600 new infections occurring daily (Pailman, 2000). It is estimated that around four million are currently infected with this figure expected to rise in the next decade.The period spanning 1994 to 2001, saw high growth of HIVIAIDS with experts agreeing that South Africa is now confronted by one of the world's serious AIDS epidemics (AIDS Training Information and Counselling Centre, 2001). This is manifest in statistics estimating that about $19 \%$ of South African people, that is 4,8 million out of a population of 40 million are HIV positive (Avert.org 2002 \& UNIAIDS 2001). Most of victims are the youth aged between 15 and 25years (Henry, 2001 \& Ministry of education, 2001).

In May 2006, Statistics South Africa published the report "mortality and causes of death in South Africa, 2003 and 2004" (Noble, 2007). The report indicates an increase in the number of adults' deaths by 79\% from 1997 to 2004. It was highlighted that the youth are the most affected.In 1997, this age group accounted for $30 \%$ of all deaths, hoewever, in 2004 it accounted for $43 \%$. These statistics show a gradual increase in the number of deaths due to HIVIAIDS every year. 


\subsection{Youths and HIVIAIDS}

The WHO (World Health Organisation) has identified young adults as the major victims of HIVIAIDS (centre for disease control, 2000). This is due to the fact that it is a stage that is associated with high risk sexual behaviour placing young adults at the risk of contracting HIVIAIDS (Makalima, 2003). In 1984, AIDS was the tenth leading cause of death among 15-24 year olds where as in 1987 it was the sixth leading killer while today it has become the leading cause of death amongst this age group (Centre for disease control, 2000). It is argued that young adults are most likely embarrassed and or resistant to condom use and are at the high risk for contracting HIVIAIDS. This is evident in the high rates of pregnancy and the dramatic increase in sexually transmitted diseases among adolescents at universities.

The UNAIDS (2001) argues that the adoption safer behaviour by the most vulnerable groups is key to success in combating the spread of HIV. Moreover, in most parts of the developing world, most of the new infections occur in young adults with young women especially vulnerable and about one third of those currently living with HIVIAIDS are aged 1524 (UNAIDS, 2001).

Many authors have put forward, the age group 15-24 as the one that is at greater risk with HIVIAIDS. Stevenson et al, (1997) opine that adolescents and young adults are at high risk of sexually transmitted diseases (STDs), including HIV, because they are at an early stage of sexual behavior and this is compounded by the fact that they frequently change sexual partners. Adolescents also perceive themselves as invulnerable to health risks, large numbers of teenagers across economic classes practice unprotected sex and many teens believe that condoms reduce pleasure or are embarrassing to obtain (Perloff, 2001). The HIV Report (2008) further states that epidemiologists agree that the current prevalence estimate of HIVIAIDS is grossly underestimated and that most cases of youth infection go undetected. The provision of candid information and life skills is thus a prerequisite for success in any HIVIAIDS response (UNAIDS, 2001).

The Henry J Kaiser Family foundation (2001) has attributed the need for focused interventions aimed at South African youth to the following reasons.

- Young people are in the process of learning sexual behaviours and are therefore more receptive to adopting safer sexual practices than older people whose sexual practices are well established.

- The targeting of youth interventions is of paramount importance because of the higher proportion of infections that occur at young ages in South Africa. It is estimated that over $60 \%$ of new infections currently occur in those between 15 and 25 years of age with women generally being infected earlier than men.

- Successful prevention initiatives could create a powerful population of uninfected adults to maintain community and household continuity.

- Prevention strategies can contribute to creating hope for the future and building a respectful relationship among the youth.

- Health promotion campaigns for other conditions have often targeted the youth in an effort to influence the adult members of their communities. This is crucial especially to young women struggling to resist sexual advances of older men.

\section{A reflection on awareness campaigns in South Africa}

There are a lot of awareness campaigns in South Africa some of which include, but are not limited to lovelife, Soul City, Khomanani, Scrutinise and Soul buddyz. Most critics point out that three outstanding campaigns which are loveLife, Khomanani and Soul city have made considerable impact on combating HIVIAIDS infections on their target audience. These campaigns have different objectives and they also use alternative approaches to raising awareness to the South African population.

The Henry J Kaiser Family Foundation (2001) identifies a number of ways that are used for raising HIVIAIDS awareness in South Africa, which include: use of posters, pamphlets and graffiti to give people information; marches, events and culture to mobilise the community using 'breaking the silence' events where people with AIDS come to talk about their experiences, or plays that show the reality of HIVIAIDS; use of protests against employers or a body that discriminates against people living with HIVIAIDS; use of prayer meetings, funerals and other community events; use of loudhailers and information tables where loudhailers are used in taxi ranks or in train carriages and setting up information tables at busy places.

The current loveLife campaign being run in South Africa since September 1999 is one of the largest and most ambitious HIVIAIDS prevention efforts. The major objective of loveLife is to positively influence adolescent sexual 
behaviour with the aim of reducing teenage pregnancy and the spread of sexually transmitted infections (STIS) among young South Africans (Rawjee,2002). LoveLife is also aimed at the reduction of the incidence of HIVIAIDS among young South Africans by at least $50 \%$ over the next five years. The focus of the loveLife campaign is for South Africans to sex. This campaign is meant to arouse interest and the campaign messages are supposed to encourage the youth to talk about sex and other issues (Rawjee, 2002).

Some critics maintain that the loveLife campaign is still incomprehensive.The effectiveness of this campaign became questionable because of its failure to achieve its original target of reducing the number of HIV infected youths to half by 2004 (Gray et al, 2007). Moreover, a major funder for loveLife, discontinued funding for the programme in December 2006 due to the apparent ineffectiveness of the programme. However, loveLife, in 2004 changed its communication strategy in an attempt to improve its effectiveness thereby repositioning its image and as well as maintaining relevance to the target audience (loveLife fact sheet, 2007).

A number of scholars argue that loveLife is proving to be of much value to South African youths (loveLife fact sheet, 2007).Statistics show that;

Approximately $85 \%$ of all South African youths have been exposed to loveLife;

- There is strong correlation between exposure to loveLife and self reported sexual behaviour,including increased abstinence, choosing to delay sexual activity, initiating sexual activity and increasing condom use;

- Participation in lovelLife programmes is statistically associated with lower odds of HIV,taking into account other likely explanatory factors;

- The rate of new infections among teenagers is showing significant declines. South Africa's third national HIV prevalence,incidence and communication survey found that HIV prevalence has declined among children aged 2-14, from $5,6 \%$ in 2002 to 2,5\% in 2008 and a decline in new infections has also been noted among teenagers aged 15-19 (loveLife fact sheet).

Khomanani,meaning 'caring together',ran since 2001 and was the foremost AIDS awareness campaign of the health department (Gray et al,2007). The Khomanani campaign utilises the mass media for broadcasting messages which include radio announcements and using situational sketches on television.

In a research carried out to measure the effectiveness of Khomanani on youth sexual behaviour, the results indicated a 'mixed and somewhat puzzling pattern of change' in the attitudes to forms of behaviour placing young people at risk of HIVIAIDS (Henry J Family Foundation,2008). The study showed that use of condoms did not change from baseline to evaluation, however, the knowledge pertaining to safe sex practices improved considerably implying that HIVIAIDS can be prevented.

This research clearly shows that the Khomanani awareness campaign was not very effecting in trying to combat the spread of HIVIAIDS because of its failure to promote effective condom use. One of the central aims of all HIVIAIDS awareness campaigns is that of promoting effective condom use and failure to do this denotes a failure of the campaign in question. However, to some extent Khomanani did foster some positive sexual behaviour to the targeted audience. Soul city and Soul buddyz are also some other campaigns which are mainly targeted at adults and children; respectively. In order to raise HIVIAIDS awareness these campaigns utilize broadcast, print and outdoor media (Parker et al, 2000).

Overally, in 2007 a major survey was carried out by Gray et al (2007) in order to assess the reception of loveLife, Soul City and Khomanani by youths. In that survey 9 in 10 South Africans (91\%) had heard about Soul city, and approximately $86 \%$ had heard of loveLife. About (61\%) indictaed that they have never heard of Khomanani.Out of those who have heard of each of these campaigns, their opinions about sexual behaviour were positive.

Moreover the Henry Henry J Kaiser family Foundationresearch (2008) which was meant gauge the impact of khomanani Soul buddyzand Lovelife and soul city on the South African population concluded that these campaigns have a positive impact on combating HIVIAIDS especially on the youths. In 2008,more than four fifths of South Africans heard or sawmore than one aspect of the campaigns (loveLife,Soul buddyz, khomanani and Soul City), from less than three quarters in 2005 (Henry J Kaiser family Foundation, 2008).

In a nutshell, thereare a number of HIVIAIDS awareness campaigns in South Africa whose main goal is that of reducing HIVIAIDS infections and promoting positive attitudes to those already affected. The group that is mostly targeted by these campaigns are the youths for they are the ones who are at greater risk for contracting the epidemic. However, despite the improved reach of these awareness campaigns,comprehensive knowledge of HIVIAIDS is poor.

\section{The health belief model}

The health belief model (HBM) is a psychological model which is useful in explaining an individual's health related 
behaviour (Denison, 1996). Moreover, it is the ideal model for addressing problem behaviours evoking health concerns including high risk-sexual behaviour and the possibility of contracting HIV. The main idea behind the HBM is that individuals must recognise a problem before they will change their attitudes and behaviours. The model has an assumption that individuals want to stay health so that they will readily indulge themselves in actions which ensure that they are in good health. This model explicates individuals' assessment and interpretation of information about their health, the importance they attribute to this information and the factors influencing their preventive action. The dominant constructs of the HBM are perceived threat, perceived barriers, perceived benefits and self-efficacy (Denison, 1996).Perceived threat comprises a combination of susceptibility and severityand an individual's opinion of the severity and consequences of the infection while perceived barriers entailan individual's perception of the tangible and psychological costs of the action to be undertaken. Self-efficacy is defined as the conviction that one can successfully execute the behaviour required to produce the outcome (Rosenstock1988). These four dominant constructs of the model which constitute the focus of most HIVIADIS awareness campaigns are the framework within which data was collected and analysed in this study.

\section{Research Methods}

This research used a combination of both qualitative and quantitative methodologies. Participants were selected using the quota sampling method. For gender equality reasons $50 \%$ of participants were female students and another $50 \%$ were males. The sample was drawn from a population of students registered at the University of Fort Hare, Alice campus. Quota sampling is a non probability sampling technique wherein the researcher ensures equal or proportionate representation of subjects depending on which trait is considered as basis of the quota (Castillo, 2009).In quota sampling, the researcher selects participants non-randomly according to some fixed quota. In this study students were selected from each year level up to third year. The remaining participants were taken from post graduate students. It has to be noted that most participants were selected from first year up to third year students because they form the majority of students at University of Fort Hare.

In order to collect data, a semi-structured questionnaire was distributed to the population under study. The following variables were measured in order to predict the impacts of HIVIAIDS awareness campaigns on the sexual behaviour of UFH students: perceived threat of HIVIAIDS; perceived barriers of HIVIAIDS; self-efficacy and exposure and perceptions towards awareness campaigns on campus.

It is important to note that these variables have been adopted from the health belief model since it purports that individuals want to stay health such they will readily indulge themselves in action that ensures they are in good health. The variables measured the impact of HIVIAIDS awareness campaigns on campus in modelling the sexual behaviour of University of Fort Hare students.

\section{Ethical Issues}

One may define ethics as a method, procedure or perspectives for deciding how to act and for analysing complex problems and issues (Richmond, 2009). Reasons of adhering to ethical norms in research are that they promote truth which is the aim of research, and errors are also reduced. Ethical clearance was obtained from the University of Fort Hare. Moreover,the following ethical principles were observed: informed consent- before distributing questionnaires all participants were informed of the objectives of the study as well as aspects of the research which may have an influence on their willingness to participate. Participants were not to be misled about matters related to the investigation in any way; The right to withdraw- participants were informed before completing the questionnaire that they had the right to withdraw during answering the questionnaire should they feel any discomfort in any way; anonymity and confidentialityparticipants were made to be aware that the data they are going to provide is going to be kept confidential. To ensure anonymity and confidentiality participants were not asked to provide their names in any part of the questionnaire and avoidance of harm- research involving human subjects is based on the principle that it should be conducted in such a way that minimises harm or risk. In this study, before answering questionnaires, participants were assured that they will suffer no lasting effect or prolonged personal discomfort because great care has been taken during the structuring of the questionnaire so that participants' well being, dignity, privacy, beliefs and values are respected. 


\section{Findings and analysis}

\subsection{Demographics}

Out of the total number of the students who participated $50 \%$ were male students and $50 \%$ were female students. In this study $100 \%$ of respondents were black Africans. About $25 \%$ participants were from each year level from first year up to third year students. The remaining $25 \%$ were post graduate students. In terms of marital status the majority of participants, which is $80 \%$, indicated that they were single and the remaining $20 \%$ indicated that they were married. There were no divorced or widowed participants in this study.

\subsection{Perceived Threats}

This section was meant to measure the beliefs of students concerning their perceived threats to contracting HIVIAIDS.The respondents had to choose their responses from a set of given responses (agree, strongly agree, disagree, and strongly disagree, not sure). On perceived threats, the responses given to questions related to students' beliefs concerning their susceptibility to contracting HIVIAIDS and the severity of the disease, showed mixed beliefs.

To begin with, none of the respondents showed that they were not sure if they were at low risk for contracting HIVIAIDS. A very small percentage which is $5 \%$ indicated that they were at very low risk for contracting the disease and $15 \%$ showed that they strongly agreed that they were at low risk for contracting HIVIAIDS. This actually tallies with what the health belief model states in terms of perceived threats when people are misinformed about the severity and susceptibility of a disease. In this case, students are viewing themselves as personally not being at risk for contracting HIVIAIDS. The greater majority of respondents which is $80 \%$ showed that they agreed to being susceptible to contracting the disease. In this case it is rational to conclude that HIVIAIDS awareness campaigns have played their part in helping students to see the severity of HIVIAIDS and perceive themselves as being susceptible to contracting it.

The majority of respondents which is $70 \%$ also showed that they did not agree that they were too young to contract HIVIAIDS, with $25 \%$ saying that they disagreed and $45 \%$ stating that they strongly disagreed. This high response rate actually tallies with other previous researches which show that there is high awareness of the HIV/IDS pandemic amongst youths although they might gradually find themselves in risky sexual behaviour. A somewhat smaller percentage which is $30 \%$ indicated that they supported the statement that they were too young to contract HIVIAIDS. As mentioned earlier this response shows that there are still a few students who are still misinformed about the nature, severity and susceptibility of HIVIAIDS. This actually is supported by the HBM which states that people often adopt a belief in personal immortality if they are misinformed of the consequences of a disease or if they are just trying to shut themselves away from the real consequences of a disease.

A greater proportion of respondents which is $70 \%$ also showed that they disagreed with the statement that they were not worried about contracting HIVIAIDS. The fact that a bigger number of respondents disagreed with the fact that they were not worried about contracting HIVIAIDS showed that they perceive themselves as being susceptible to contracting HIVIAIDS. HIVIAIDS awareness campaigns in this case can be said to have achieved their target, for they are mainly aimed at defining populations that are at risk, risk levels and also personalising risk based on a person's features of behaviour. The remaining $30 \%$ showed that they were not worried about contracting HIVIAIDS. About $75 \%$ of the respondents disagreed with the statement that they were too young to get an HIV infection, with $20 \%$ indicating that they agreed with the statement and the remaining $5 \%$ indicating that they were not sure.

Lastly $70 \%$ of the respondents indicated that they disagreed with the statement that there is no need for VCT (voluntary counselling and testing) since they do not have any symptoms of HIVIAIDS. About $10 \%$ of the respondents indicated that they strongly disagreed with the statement. The remaining $20 \%$ indicated that they supported the statement that there was no need for them to go for VCT since they did not have any symptoms of HIVIAIDS.

To cap it all, in terms of perceived threats, the grater majority of respondents viewed themselves as personally at risk for contracting HIVIAIDS. The fact that, for example ,a greater proportion of respondents indicated that they were willing to go for VCT despite the fact that they did not have any symptoms of HIVIAIDS clearly shows that the perceived threats of HIVIAIDS infection is a well known phenomenon to most students.

On perceived threats, it is important to note that a survey carried out by the Henry J Kaiser Family Foundation (2008) seems to converge with the research in question since it was concluded that of those exposed to LoveLife, Soul Buddyz,Khomanani and Soul City awareness messages were best received by 15-24 year olds, which is the main target of these campaigns, with $90 \%$ coverage. 


\subsection{Perceived barriers}

This was meant to measure the degree to which HIVIAIDS awareness campaigns have reached in terms of trying to demystify the belief that HIVIAIDS is a death penalty. This is of paramount importance because as stated by Rosenstock (1988) the potential negative aspects of a particular health action or perceived barriers may act as impediments to undertaking the recommended behaviour. If perceived barriers of individuals are very low it means that they will readily indulge in health seeking behaviour such as VCT and effective condom use. High perceived barriers will result in risky behaviour and unwillingness to go for VCT and use of condoms effectively.

To begin with, $70 \%$ indicated that they believed that if ever they got the HIVIAIDS infection they would eventually die, with $60 \%$ indicating that they agreed and $10 \%$ indicating that they strongly agreed with the statement. This response shows that the majority of respondents believed that a lack of future or cessation of 'everything' follows a positive diagnosis (Day et al, 2003). This is likely to lead students to the refusal to go for VCT because of fear of death. This actually concurs with a research carried out by Shisana et al (2003) which reviewed that resistance of participants to HIV testing has been attributed to fear of being HIV positive caused by the association between AIDS and death. About $20 \%$ of the respondents indicated that they disagreed with the fact that they if they got HIVIAIDS infection they would eventually die. The remaining $10 \%$ indicated that they strongly disagreed with this statement. This response from a smaller proportion suggests that HIVIAIDS awareness campaigns might have done very little in trying to demystify the fact that HIVIAIDS is a death penalty.

The majority of respondents in this case, $60 \%$ also indicated that if they got an HIVIAIDS infection they would be avoided. Similarly $70 \%$ indicated that if they got HIVIAIDS infection their family relationship would be strained. This clearly shows that there is still a lot of fear associated with HIV infection and acceptance by other people. The stigma that is associated with HIVIAIDS infection is a major barrier to VCT because students would chose to live without knowing their HIV status rather than face the challenge of being stigmatised if their results for HIV test turn out positive.As was concluded by other previous researches most people who are not sure about their HIVIAIDS status mostly engage in risky sexual behaviour because they often believe in personal immortality. HIVIAIDS awareness campaigns thus seem not to have made a lot of impact in reducing the stigma associated with HIVIAIDS infection.However, almost $40 \%$ of the respondents indicated that they disagreed that they would be avoided if they contracted HIVIAIDS, while $5 \%$ of the respondents indicated that they were not sure that their family relationships would be strained if they contracted HIVIAIDS.

Respondents constituting, 75\% disagreed with the statement that they were afraid to negotiate safe sex with their partners, with $55 \%$ stating that they disagreed and $20 \%$ saying that they strongly disagreed. A minority of respondents which is $15 \%$ indicated that they were afraid to negotiate safe sex with their partners.15\% of the respondents also indicated that if they negotiated safe sex with their partners, their partners would think that they had a sexually transmitted disease (STD). About $80 \%$ indicated that they did not agree with the statement that if they negotiated safe sex, their partners would think that they had an STD. The remaining $5 \%$ showed that they were not sure.

In terms of negotiation of safer sexual behaviour there seems to be an awareness of the consequences of risky sexual behaviour amongst students, since the majority indicated that they were not afraid to negotiate safe sex and disagreed with the statement that if they negotiate safe sex their partners would think that they have a sexually transmitted diease. Campaigns in terms of safer sexual behaviour seem to have done a great deal of awareness to students since the majority seem to have the courage to indulge in safer sexual practices.

\subsection{Self efficacy}

A small percentage, which is $25 \%$, indicated that condoms decrease pleasure during sex. The remaining $75 \%$ indicated that condoms do not decrease pleasure during sex. This clearly indicates that most students are not still subject to the myth that surrounds the use of condoms during sex. This suggests that HIVIAIDS awareness campaigns have managed to demystify the myth surrounding condom use.

Out of the respondents in the sample,35\% indicated that it is embarrassing to buy condoms and $65 \%$ indicated that they disagreed condoms are embarrassing to purchase. This is also evidence to show that in terms of effective condom use, HIVIAIDS awareness campaigns have managed to foster positive attitudes on students.

However, $80 \%$ of respondents indicated that they worry less about contracting HIVIAIDS when using condoms during sex. The remaining $20 \%$ indicated that they disagreed with the statement that they would worry less about contracting HIVIAIDS. Students seem to be well informed of the benefits of using condoms when having sex. 
Understandably, $95 \%$ of the respondents indicated that they would worry less about contracting HIVIAIDS when they are abstinent. 40\% showed that they agreed that they would worry less when they were abstinent and $55 \%$ indicated that they strongly agreed with the statement. The remaining $5 \%$ indicated that they disagreed with the fact that they would worry less about contracting HIVIAIDS when they are abstinent.

Of the respondents who participated in the study, $80 \%$ of them indicated that condomising is the best way to avoid contracting HIVIAIDS with $75 \%$ saying they agreed and 25\% saying they strongly agreed. The remaining $20 \%$ people indicated that they disagreed with the fact that condomising is the best way to avoid contracting HIVIAIDS.

Overall, respondents showed high self efficacy when it comes to using condoms. Many disagreed with myths such as, condoms decrease pleasure during sex and it is embarrassing to purchase condoms. They also indicated that they would worry less about contracting HIVIAIDS when they use condoms.It is important to note that the majority perceived abstinence as the best way to avoid contracting HIVIAIDS. This high self efficacy really shows that awareness campaigns have done a great deal in order to promote effective condom use because the main objective of HIVIAIDS awareness campaigns is that of promoting safe sexual behaviour through the use of condoms effectively. As pointed out by Bandura (1990) there is a strong link between self-efficacy and condom use because in order to exercise personal control in sexual situations that carry a risk of infection it requires individuals to possess self-efficacy as well as skills to communicate about sexuality and safe sex practices and negotiating their use.

The smaller proportion of respondents that displayed a low degree of self efficacy cannot be given a blind eye. As already indicated above, 25\% clearly indicated that condoms decrease pleasure during sex and $35 \%$ indicated that they were embarrassed to purchase condoms. As indicated by Brafford and Beck (1991) in the HBM sometimes safer sex practices are hindered when self-protection conflicts with interpersonal pressures and sentiments. In this case, the minority respondents who showed low self efficacy are likely to find themselves indulging in risky sexual behaviour.This is supported by Brafford and Beck (1991) when they point out that the weaker the perceived self efficacy the more such social and effective factors can increase the likelihood of risky sexual behaviour.

\subsection{Perceptions on and exposure to HIV/AIDS awareness campaigns}

In this study, $100 \%$ of the participants indicated that they have heard of awareness campaigns on campus and they also thought that HIVIAIDS awareness campaigns are important. Almost $95 \%$ of the participants indicated that they have gained new knowledge by attending HIVIAIDS awareness campaigns and the remaining $5 \%$ indicated that they did not gain any new information. About $80 \%$ indicated that they knew the HIVIAIDS awareness logo whilst the remaining $20 \%$ indicated that they were not aware of the logo. $45 \%$ of the respondents indicated that they have been part of an HIVIAIDS awareness initiative on campus and the remaining 55\% indicated that they have never been part of an awareness initiative on campus.

One can conclude that most students at the University of Fort Hare, Alice campus have been exposed to awareness campaigns. Respondents also indicated that they thought that awareness campaigns were important and that they had attained a great deal of new information from campaign messages. The few that indicated that they were not part of an awareness campaign on campus and those that also indicated that they never gained new knowledge through HIVIAIDS awareness campaigns might to explain the minority that displayed low self efficacy, high perceived threats and high perceived barriers. This might be so, because many previous researches have indicated that there is a strong relationship between exposure to awareness campaigns and high self efficacy, low perceived barriers and low perceived threats. A good example is the research that was carried by love Life (2007) where it was concluded that there is strong correlation between exposure to love Life and self reported sexual behaviour, including increased abstinence, choosing to delay sexual activity, initiating sexual activity and increasing condom use.

\section{Conclusion}

This study sought to establish whether awareness and prevention campaigns are exerting any significant positive changes on the sexual behaviour of students at the University of Fort Hare and also to establish whether effective condom use at the University of Fort Hare has been promoted by HIVIAIDS awareness campaigns. It is against this background that the following conclusions can be drawn from the research findings. HIVIAIDS awareness campaigns have been found to be effective to a larger extent in promoting safer sexual behaviour to the sample that participated in this study. Awareness campaigns were important and provided great deal of new information from campaign messages resulting in safe sex just like in other studies (Limpopo lovelife studies; Janssen \& Janssen : 2008; Hacalara project). 
It was noted that most of the students who participated, perceived themselves as highly susceptible to contracting HIVIAIDS which in turn prompts them to engage in safe sexual behaviour. HIVIAIDS awareness campaigns have, therefore assisted students to see the severity of HIVIAIDS, prompting them to accept that they are susceptible to contracting HIVIAIDS and thus leading them to opt for safe sexual behaviour.

The effectiveness of campaigns has been greatly questioned because of the high perceived barriers, for example, the fear that one would be avoided and relationships would be strained if people find out that one is HIV positive. As pointed out earlier, high perceived barriers will lead people to avoid health seeking behaviour and readily indulge in risky sexual behaviour.

From the responses taken from a sample of students at the University of Fort Hare, many students displayed that they could use condoms effectively. However, this seems to contradict the fact that many participants showed high perceived barriers and some of them in terms of perceived threats indicated that they were too young to contract HIVIAIDS.This suggests that students have courage to negotiate safe sex and are not embarrassed to purchase condoms but it might be less likely that they use condoms consistently.

Based on the conclusion from the research findings, the following recommendations were made. There is need for future studies to investigate how often or consistent students are with the use of condoms. HIVIAIDS awareness campaigns need also to help in reducing perceived barriers through provision of antiretroviral therapy to those infected. This might greatly reduce stigma associated with HIVIAIDS infection.

There is also need for HIVIAIDS awareness campaigns to launch campaigns that are meant to end the stigma associated with HIV infection. This can be done through some of the following actions: use of posters, pamphlets and graffiti to give students information; use of prayer meetings and setting up information tables at busy places like the students centre. If these are used effectively they would help students and the Fort Hare community at large to accept those that are infected by HIVIAIDS. If stigma associated which HIVIAIDS infection is halted the number of those who go for VCT is also likely to increase because students would no longer be afraid of stigmatisation by others if they are infected.

\section{References}

Asmal K. 2001. Protecting the Children's rights to innocents,paper presented at a conference on sexuality education inSouth Africa.

AIDS Training Information and Counselling Centre (ATICC) .2001.ATICC Report of Highlights: April 2001 - June 2002

Avert .org .2002.Young people with HIV and AIDSaccessed online.

Bandura A.1990.Self-Efficacy: Towards a Unifying Theory of Behavioural Change,psychological Review (84), 191-215.

Balding J and Regis D.1993."Participation and information-Why young people need more than 'facts' in HIV and AIDS education." HYGIE Journal 12(10)

Bloom SW (1986) Institutional Trends in Medical Sociology; Journal of Health and Social behaviour 27(1).

Brafford L.J. and Beck K.H. 1991.Development and Validation of a Condom Self-efficacy Scale for College Students, Journal of American College Health(39), 5

Castillo J. J .2009.Non Probability Sampling available onlinehttp://www.experiment-resources.com/non- probability-sampling.html

Centre for disease control and Prevention accessed from www.edenpin.org/hiv/faqvirus.htm.

Chetty D.2000.Institutionalising the responds to HIVIAIDS in the South African

University sector: A SAUVCA analysis; SAUCVA Occasional Publications and Reports

Creswell J W. 2005. Educational research. Planning, conduct and evaluatingquantitative and Qualitative research.2nd edition. Upper River, New Jersey: Pearson Prentice Hall

Makalima, C.2003.Perceptions of grade six and seven Xhosa learners with regard to the HIVIAIDS life skills education programme. Unpublished masters thesis Nelson Mandela Metropolitan University, Port Elizabeth

Cox, F D .1996. The AIDS booklet (4thed).Boston: McGraw-Hill.

Cusak L and Singh S .1994.HIVIAIDS and care.Practical approaches:London: Chapman and Hall.

Denison, J. (August 1996), AIDSCAP Behavioural Research Unity

Day, J. H., et al. 2003. Attitudes to HIV voluntary counsellingand testing among mineworkers in South Africa: will availability of antiretroviral therapy encourage testing? AIDS Care 15(5).

Glans K, Ramer B, K. and Lewis FM.2003. Health behaviour and health education: Theory, Research and Practice; San Francisco, JoséBass.

Gray A,Govendor M,Gengier T,Singh J.2007.In ljumba P,Barron P eds.South African Health Review;Health Systems Trust:Durban.

Henry,J.Kaiser Family Foundation. 2001.Impeding Catastrophe revisited:An update on the HIVIAIDS epidemic in South Africa.Lovelife: Talk about Associates; Parklands, South Africa.

Henry J Kaiser Family Foundation.2008. Young South Africans,Broadcast media and HIV/AIDS Awareness:Results of a National Survey. HIV Report.2008 .Adolescents and HIV.Johns Hopkins AIDS service. 
Kalichman,S ,C., Leickness C. Simbayi, Demetria Cain, Sean Jooste, Donald Skinner, and Charsey C. 2006. Generalizing a model of health behaviour change and AIDS stigma for use with sexually transmitted infection clinic patients in Cape Town, South Africa. AIDS Care 18(3).

Kumar, R. 1996. Research methodology. New York: Sage publications

loveLife. 2004. loveLife 2004 Report on Activities and Progress. Parklands, South Africa: loveLife

loveLife.2007.Lovelife fact sheet.,Parklands,South Africa:loveLife.

Leclerc-Madlala, Suzanne. 1997. Infect One, Infect All: Zulu Youth Response to the AIDS Epidemic in South Africa. Medical Anthropology.

May,T. 1993.Social Research. Buckingham: Open University press. McKeganey

Noble A.2007.South Africa HIV and AIDS statistics summery.

Parry C, Abdool-Karim Q. 1999. Country Report: Substance abuse and HIVIAIDS in South Africa. Proceedings of 2nd Global Research Network Meeting on HIV Prevention Drug-Using Populations, Atlanta, Washington, DC: US Department of Health and Human Service.

Parker, Richard and Peter Aggleton. 2003. HIV and AIDS-related stigma and discrimination:a conceptual framework and implications for action, Social Science andMedicinie, (15) 24.

Perloff,R.M,2001.Persuading people to have safer sex.Application of social science to the AIDS crisis. London: Lawrence Erlbaum Associates Publishers.

Ragon BM.1995.The effect of a single Affective HIVIAIDS Educational Programme on college students' knowledge and Attitudes;AIDS Education and Prevention. (221) 231

Rosenstock.1988.Social Learning Theory and Health Belief Model; Health Education Quarterly 15 (2).

Togni, L.1997.AIDS in South Africa and on the African continent:Cape Town, KagisoPublishers.

Sarantakos, S. (2002). Social Research. New York: Palgrave.

Shisana, O, et al. 2005.South African National HIV Prevalence, HIV Incidence, Communication and Behaviour Survey. Cape Town: HSRCPress.

Siyaya V, W. 2007.The impact of HIVIAIDS peer education programme on condom use of fulltime students at the University of Zululand main campus. Unpublished masters thesis, University of Zululand.

Shisana, O, et al. 2005.South African National HIV Prevalence,HIVIncidence, Communication and Behaviour Survey. Cape Town: HSRCPress.

Stone G.1979.Patient compliance and the role of the expert.Journal of Social Issues 35 (1).

UNAIDS. 2006. AIDS epidemic update: December 2006. Geneva: WHO

UNAIDS.2001. Report on the global HIVIAIDS epidemic, 10th global Report: Geneva. Joint United Nations Programme on AIDS

Van Dyk, A.2005.HIVIAIDS care and counselling, A multidisciplinary approach .Cape Town: Pearson Education

Rawjee P.V. 2002.Effective HIVIAIDS Communication Campaigns: A casestudy of an HIVIAIDS Awareness Campaign Targeted at Young Adults at a Tertiary Institution. Unpublished masters thesis, University of Natal, Durban. 